Artigo de Revisão

\title{
Da escola de ofício a profissão educação física: a constituição do habitus profissional de professor
}

\author{
Samuel de Souza Neto ${ }^{1,2}$ \\ Larissa Cerignoni Benites ${ }^{2}$ \\ Mellissa Fernanda Gomes da Silva ${ }^{2}$ \\ ${ }^{1}$ UNESP - Univer. Estadual Paulista, Instituto de Biociências, Departamento de \\ Educação, Rio Claro, SP, Brasil \\ ${ }^{2}$ UNESP - Univer. Estadual Paulista, Instituto de Biociências, PPGCM/ NEPEF; \\ DFPPE de Rio Claro, SP, Brasil
}

\begin{abstract}
Resumo: Este estudo trata da questão dos elementos que constituem o habitus profissional de professor, tendo na construção da identidade docente o ponto de partida. Como resultado concluiu-se que o habitus profissional é formado por uma gramática geradora de práticas, rotinas e esquemas que envolvem ações didáticas, hexis corporal e postura.
\end{abstract}

Palavras-chave: Educação Física. Professor. Habitus. Profissão.

\section{School of craft the profession of physical education: the constituition of the professional teacher habitus}

\begin{abstract}
Study addresses the question of elements that constitute the habitus of professional teacher, and the construction of teacher identity the starting point. As a result it was concluded that the professional habitus consists of a grammar-generating practices, routines and schemes involving didactic actions, hexis body and posture.
\end{abstract}

Key Words: Physical Education. Habitus. Profession.

\section{Introdução}

Este estudo emergiu num momento em que o movimento da profissionalização do magistério vem sendo discutido na sociedade brasileira, tendo suas incursões nas reformas dos programas de formação profissional ou na perspectiva de se formar um professor mais poderoso que traga respostas ou soluções para o ultrajante fracasso escolar.

De um lado questiona-se o neoliberalismo das reformas, apontando-se para o funcionalismo da idéia de profissão, enquanto que de outro observa-se a proletarização do professor e a terceirização da educação e do ensino.

Assim, para além desse pêndulo, este trabalho busca apontar que não é possível desconsiderar a atual estrutura ou sistema no qual estamos vivendo, bem como não é possível negar a cultura e historicidade da qual cada homem é portador em seu corpo. O que implica em considerar a sua subjetividade. Portanto, o que se busca discutir nesse texto diz respeito a perspectiva de mediação que pode ocorrer entre o objetivismo e o subjetivismo, visando superálos, tendo como chave de leitura a teoria do habitus.

Dessa forma este trabalho tem como objetivo identificar nos elementos constituintes do habitus profissional de professor as categorias pedagógicas que possam contribuir para uma possível "gênese" da profissão docente pautada nos saberes, práticas, valores. Como ponto de partida opta-se, inicialmente, pela delimitação da compreensão do universo de algumas categorias, apontando também a questão de estudo na forma de um problema e ou pressuposto (hipótese) que nos movem na direção de possíveis encaminhamentos.

No âmbito desse processo por profissão vamos entender uma determinada atividade que conta com a presença de um conjunto de atributos, características próprias. Porém, no que diz respeito à idéia de profissão docente esta é considerada por alguns autores (PAPI, 2005) como uma semi-profissão ou como ofício.

$\mathrm{Na}$ realidade brasileira, em virtude da adoção do modelo continental europeu, vinculado ao campo de trabalho não se leva veemente em consideração as distinções peculiares do modelo anglo saxônico e/ou anglo-americano em que se opera uma radical separação, valorizando a qualidade da prestação de serviços (COELHO, 1999). Em nosso país, bem como em outros países latinos-americanos ou europeu tudo é profissão, sendo usado indistintamente, assim como nesse trabalho para este momento. Porém, é uma realidade em transformação tanto no Brasil como na Europa.

Neste contexto, Pintassilgo (1999) considera o professor como prático e como intelectual. Como 
prático, verdadeiro artesão do ensino, possuindo uma visão global do ato de ensinar, tendo como norte deste exercício "um saber de experiência feito" (p. 97), pautado na afetividade e imaginação na organização de sua atividade. Como intelectual, ao menos idealmente, quando assume sua autonomia e criticidade em relação aos saberes e poderes, bem como em relação à criação de seu estilo próprio de exercer a profissão, fazendo com que o docente tenha como referência normas deontológicas e éticas, dando sentido a sua profissão.

Entretanto cabe evidenciar que no campo do trabalho tanto o ofício como a profissão são vistos como ocupações. No geral pode-se colocar que a ocupação é o modo genérico de organizar o trabalho, sendo apenas "emprego" na sua forma menos organizada e "profissão" na sua forma mais organizada.

Qualquer que seja a forma de definir 'profissão' ela é, antes de tudo e principalmente, um tipo específico de trabalho especializado [...] Obviamente, uma grande parcela de trabalho é efetuada em casa e na comunidade, mas boa parte dele não é reconhecida como trabalho: algumas vezes, porque não é formalmente recompensada; outras, porque não se realiza em tempo integral. Outros tipos de trabalho são pagos e realizados em tempo integral, mas informalmente, à margem da economia oficial. O restante desse amplo universo de trabalho é composto de ocupações e ofícios desempenhados na economia reconhecida oficialmente. É aí que encontramos as profissões, listadas como um tipo especial de ocupação nas modernas classificações oficiais [...] "muitas profissões tiveram suas origens na economia informal e só depois se tornaram reconhecidas oficialmente" (FREIDSON, 1998, p. $142-143)$.

De modo que a terminologia acaba remetendo a um método formal lógico, possibilitando 0 controle e a organização do trabalho (FREIDSON, 1998).

Assim por profissionalização vamos entender o processo socializador de aquisição de características inerentes ao exercício profissional, estando estritamente ligada ao termo profissionalidade, ou seja, como as características e capacidades específicas da profissão docente (IMBERNÓN, 2004, p.24).

Porém, a utilização do termo profissionalidade é recente, da mesma forma que a palavra em si, pois na língua portuguesa não é encontrada, Em sua origem italiana pode aparecer como sinônimo de profissionalismo, pois o substantivo profissionalidade corresponde ao caráter profissional de uma atividade econômica. Da mesma forma que é também entendida como a soma de conhecimentos, capacidades e experiências que se põem em jogo nessa atividade.

Nesta compreensão o debate sobre a profissionalidade docente passa, necessariamente, pelos termos profissão, profissionalismo e profissionalização, sendo apresentada como sinônimo de profissionalismo. Por exemplo: "profissionalismo - alguns estudos dizem profissionalidade - características e capacidades específicas da profissão; profissionalização: processo socializador de aquisição de tais características" (IMBERNÓN, 2004, p. 24).

Desta forma aborda-se o termo profissionalidade como parte integrante do termo profissionalismo, definindo 0 processo de profissionalização como o meio pelo qual o professor adquire tais características e valores próprios da profissão, ou seja, a profissionalidade docente.

No entanto, Contreras (2002), ao tratar do processo de profissionalização docente, vai colocar que alguns autores evitam utilizar o termo "profissionalismo", por conter uma descrição ideológica, junto aos valores anteriores, acerca do status e dos privilégios sociais e trabalhistas aos quais se aspira na profissão docente.

Para o autor, o termo profissionalidade surge no âmbito de se oferecer um novo sentido ao termo profissionalismo: "Em seu lugar, optou-se pelo termo profissionalidade, como modo de resgatar o que de positivo tem a idéia de profissional no contexto das funções inerentes ao trabalho da docência." (p. 73).

Assim falar de "profissionalidade significa, nessa perspectiva, não só descrever o desempenho do trabalho de ensinar, mas também expressar valores e pretensões que se deseja alcançar e desenvolver nesta profissão" (p. 74). Portanto, a profissionalidade docente se desenvolve, englobando três dimensões: obrigação moral, compromisso com a comunidade e competência profissional que é mais do que o saber fazer e envolve as outras duas dimensões. Dessa forma, essas três dimensões têm como objetivo, no seu conjunto, apresentar os componentes que estão envolvidos com a tarefa de educar e com o exercício de sua profissionalidade dentro de um contexto de produção da cultura.

No âmbito dessa cultura os saberes docentes foram se constituindo também como algo plural no âmbito sócio-cultural da profissão, podendo apresentar modificações com o passar do tempo (BENITES, 2007). Neste contexto, para Benites (2007) o termo saber estaria incluindo informações, crenças, habilidades e aptidões relacionadas a uma determinada profissão. Assim, para a autora, em relação ao trabalho docente, o mesmo pode envolver uma grande teia de saberes, perpassando a matéria a ser ensinada, a fundamentação teórica sobre a ação docente, saber preparar e dirigir atividades, saber avaliar, utilizar a pesquisa e a inovação. Entre outras palavras este arcabouço envolveria um conjunto de saberes: curriculares, das ciências da educação, da tradição pedagógica, disciplinares, da ação pedagógica e da experiência, podendo 
apresentar uma variação de autor [PIMENTA (1997); TARDIF(2002)] para autor em sua sistematização de acordo com o recorte adotado, podendo não ter o mesmo significado.

Da mesma forma que esta cultura engendra um corpo de saberes que dão sustentação a profissionalidade ela também aponta para a composição de uma identidade entendida, neste estudo, como o processo de construção social de um sujeito historicamente situado.

De acordo com Benites (2007, p.10) em se tratando da identidade profissional, esta se constrói com base na significação social da profissão e de suas tradições. Neste itinerário, a profissão de professor, como as demais profissões, emergiu num dado contexto como resposta às necessidades postas pelas sociedades, constituindo-se num corpo organizado de saberes e um conjunto de normas e valores. Estes saberes, valores e normas, com o passar do tempo, materializam-se na forma de uma tradição, criando ou gerando uma identidade social que envolve a criação de procedimentos institucionalizados de formação específica, especializada e prolongados; constituição de associações profissionais e manifestação de um estatuto de legalidade.

Dessa forma tanto a questão da profissionalidade, como os saberes docentes e a identidade profissional, bem como os conceitos de profissão ou formação trazem como compreensão desse processo a idéia de cultura. A cultura pode ser expressa por meio de seus valores e sentimentos, rituais, instituições, objetos e costumes que circundam a vida individual e coletiva da sociedade. Portanto, ao “'viver' uma determinada cultura, estaremos reproduzindo-a, reinterpretando-a e transformando-a "( JUNIOR, 2007, p. 14).

Assim, Knoblauch (2007, p.4-5) assinala que a escola, enquanto instituição é responsável por transmitir um conjunto de esquemas fundamentais, na forma de uma "'força formadora de hábitos', baseados numa mesma cultura”. De modo que a escola teria a função de transmitir um habitus cultivado, um sistema de disposição geral baseado numa mesma cultura, caracterizando a internalização de uma cultura, a incorporação do habitus, para que este produza práticas. Porém, um mesmo habitus, por sua vez, admite práticas diferenciadas como um produto da relação entre o habitus e uma determinada situação conjuntural.

A noção de habitus será entendida na mesma dimensão que Pierre Bourdieu (1989) atribuiu ao mesmo, considerando que tende a conformar e orientar a ação dos indivíduos, pois, na medida que influencia o relacionamento entre pessoas, "produz alguns produtos" que tendem à perpetuar o costume de uma cultura.

Nesta direção, Setton (2002) assinala que o habitus é uma noção que auxilia a pensar as características de uma identidade social, de uma experiência biográfica, um sistema de orientação, ora consciente, ora inconsciente. Portanto, com base nos estudos de Bourdieu (1989, 1994a, 1994b, 1994c, 1994d, 1994e, 1996, 2007), verifica-se que o habitus traduz exatamente 0 modo de ser professor, contemplando características específicas que podem nos auxiliar na compreensão da prática profissional do professor, bem como proporcionar uma leitura mais objetiva sobre a figura do professor, constituindo-se no foco deste trabalho que se elucida com a seguinte questão ou problemática:

Quais são os elementos constituintes do habitus profissional de professor de Educação Física que contribuem para a construção da identidade docente, mas que não são revelados a priori?

$\mathrm{Na}$ busca de respostas a este problema partese do pressuposto de que embora o conhecimento específico do professor seja pautado num saber tácito e na academia/formação os conhecimentos apareçam pré-configurados não será possível avançar na questão pedagógica se não se efetivar uma mediação entre o objetivismo (estruturalismo) e o subjetivismo (construtivismo).

\section{A teoria do habitus: uma gramática para a leitura da profissão professor \\ Bourdieu (1989), num raro texto,} autobiográfico, assinala que se tivesse que caracterizar o seu trabalho em duas palavras, ou seja, se tivesse que Ihe aplicar um rótulo falaria de constructuvist structuralism ou de structuralism constructuvist, tomando a palavra estruturalismo no sentido daquele que lhe é dado pela tradição saussuriana e lévi-straussiana.

O texto assinala para a perspectiva de se tentar entender como determinados grupos sociais ou instituições (igreja, política, ciência, arte, esporte, educação, mídia etc) demarcavam o seu "território", na luta política pela obtenção de um espaço social, caracterizado por um capital específico, capital cultural, "capital simbólico", bem como organizavam a sua identidade em termos de prática social e representação.

$\mathrm{Na}$ visão do autor, a ciência social, tanto a antropologia como a sociologia e a história, oscila entre dois pontos de vista, aparentemente incompatíveis: o objetivismo (ou fisicalismo = física social) e o subjetivismo [psicologismo (que pode tomar diversas colorações fenomenológica, semiológica etc)]. O primeiro pode tratar os fatos sociais como coisas e deixar de lado tudo o que eles devem-se ao fato de serem objetos de conhecimento (ou de desconhecimento) na existência social; enquanto que o segundo, pode reduzir o mundo social às representações que dele fazem parte os agentes.

Para o autor, ambos os momentos estão numa relação dialética, uma vez que se 0 
momento subjetivista está próximo quando o tomamos isoladamente nas análises interacionalistas, o mesmo aparece separado do momento objetivista quando se observa a posição (pontos de vista) dos respectivos agente na estrutura.

Dessa forma para romper com esta oposição artificial, que se estabeleceu entre as estruturas e as representações, é preciso, antes, romper com o modo de pensamento substancialista que leva a não reconhecer nenhuma outra realidade, além das que se oferecem à intuição direta na experiência cotidiana dos indivíduos e grupos.

Mas há uma grande probabilidade de que o espaço, isto é, as relações, escape ao leitor, apesar do recurso a diagramas (e a analise fatorial): de um lado, porque o modo de pensamento substancialista é mais fácil, mais "natural"; e, depois, porque, como muitas vezes acontece, os meios que se é obrigado a empregar para construir o espaço social e para torná-lo manifesto podem esconder os resultados que eles permitem alcançar. Os grupos que se devem construir para objetivar as posições que eles ocupam escondem estas posições, (...).

É possível, a esta altura da exposição, comparar o espaço social a um espaço geográfico no interior do qual se recortam regiões. Mas este espaço é construído de tal maneira que quanto mais próximos estiverem os grupos ou instituições ali situados, mais propriedades eles terão em comum; quanto mais afastados menos propriedades em comum eles terão (BOURDIEU, 1989, p. 154 o grifo é nosso).

No geral, o autor conclui que o mal entendido, na leitura das análises que propõe, resulta do fato de que as classes, no papel, correm o risco de serem aprendidas como grupos reais. O espaço social está construído de modo que os agentes, que ocupam posições semelhantes ou vizinhas, estão colocados em condições semelhantes e submetidos a condicionamentos semelhantes, podendo-se produzir práticas também semelhantes.

De fato, as distâncias sociais estão inscritas nos corpos, ou, mais precisamente na relação com o corpo, com a linguagem e com o tempo (outros aspectos estruturais da prática que a visão subjetivista ignora).

Se acrescentarmos que esse sense of one's place, bem como as afinidades de Habitus vividas como simpatia ou antipatia, estão na origem de todas as formas de cooptação amizades, amores, casamentos, associações, etc. - logo, de todas as ligações duráveis e às vezes juridicamente sancionadas, perceberemos que tudo nos leva a pensar que as classes no papel são grupos reais, e tanto mais reais quanto mais bem construído for 0 espaço e menores unidades recortadas nesse espaço. (p. 155)

Pondera-se que, assim como o subjetivismo predispõe a reduzir as estruturas às interações, o objetivismo tende a deduzir as ações e interações da estrutura, consistindo-se num erro considerar as classes ou os grupos no papel como classes e grupos reais.

Assim, o erro maior, o erro teoricista encontrado em Marx, consistiria em tratar as classes no papel como classes reais, em concluir, da homogeneidade objetiva das condições, dos condicionamentos e, portanto das disposições, que decorre da identidade de posições no espaço social, a existência enquanto grupo unificado, enquanto classe. (p. 156)

Como saída, a noção de espaço social permitiria escapar à alternativa do nominalismo e do realismo em matéria de classes sociais, dado que somos nós que construímos o espaço social.

Em outros termos, através da distribuição das propriedades, o mundo social apresenta-se, objetivamente, como um sistema simbólico que é organizado segundo a lógica da diferença, do desvio diferencial. O espaço social tende a funcionar como um espaço simbólico, um espaço de estilos de vida e de grupos de estatuto, caracterizados por diferentes estilos de vida.

Assim, a percepção do mundo social é produto de uma dupla estruturação: do lado objetivo, ela é socialmente estruturada porque as propriedades atribuídas aos agentes e instituições apresentam-se em combinações com probabilidades muito desiguais: assim como os animais com penas têm mais possibilidades de ter asas do que os animais com pêlo, (...). Do lado subjetivo, ela é estruturada porque os esquemas de percepção e apreciação, em especial os que estão inscritos na linguagem, exprimem o estado das relações de poder simbólico: penso, por exemplo, nos pares de adjetivos: pesado/leve, brilhante/apagado, etc. (p. 160161)

Neste contexto encontramos também as lutas simbólicas, envolvendo a apreensão da percepção do mundo social no âmbito do lado objetivo - relacionadas a ações de representação individual e coletiva destinadas a mostrar e a fazer valerem determinadas realidades como o manifesto de um grupo, buscando a sua visibilidade e/ou ao nível individual, visando a apresentação de si, a manipulação da imagem de si e, sobretudo, de sua posição no espaço social - e do lado subjetivo - tentando mudar as categorias de percepção e apreciação do mundo social, as estruturas cognitivas e avaliatórias: as categorias de percepção, os sistemas de classificação (as palavras, os nomes que constroem a realidade social).

Essas lutas simbólicas, tanto as lutas individuais da existência cotidiana como as lutas coletivas e organizadas da vida política, têm uma lógica específica que lhes confere uma autonomia real em relação às estruturas em que estão enraizadas. Pelo fato de que o capital simbólico não é outra coisa senão o capital econômico ou cultural quando conhecido e reconhecido, quando conhecido 
segundo as categorias de percepção que ele impõe, as relações de força tendem a reproduzir e reforçar as relações de força que constituem a estrutura do espaço social. Em termos mais concretos, a legitimação da ordem social não é produto, como alguns acreditam, de uma ação deliberadamente orientada de propaganda ou de imposição simbólica; ele resulta do fato de que os agentes aplicam às estruturas objetivas do mundo social estruturas de percepção e apreciação que são provenientes dessas estruturas objetivas e tendem por isso a perceber o mundo como evidente (p. 163).

Desse modo, as relações objetivas de poder tendem a se reproduzir nas relações de poder simbólico, bem como na luta simbólica pelo monopólio da nominação legítima, produção do senso comum, pois os agentes investem o capital simbólico que adquiriram e que pode ser juridicamente garantido, como os títulos escolares - títulos de propriedade simbólica que dão direito às vantagens de reconhecimento.

A legalização do capital simbólico confere a uma perspectiva um valor absoluto, universal, livrando-a assim da relatividade que é inerente, por definição, a qualquer ponto de vista, como visão tomada a partir de um ponto particular do espaço social.

Há um ponto de vista oficial, que é o ponto de vista das autoridades e que se exprime no discurso oficial. Esse discurso, (...), preenche três funções: em primeiro lugar, ele opera um diagnóstico, (...), um ato de conhecimento que obtém o reconhecimento e que, com muita freqüência, tende a afirmar o que uma pessoa ou uma coisa é, e o que ela é universalmente, para qualquer homem possível, logo, objetivamente. (...). Em segundo, o discurso administrativo, através das diretivas, ordens, prescrições, etc., diz que as pessoas têm de fazer, considerando o que elas são. Em terceiro, ele diz o que as pessoas realmente fizeram, como nos relatórios oficiais. (p. 164)

Enfim, o que se tem é, de fato, um jogo em que o poder simbólico tem o poder de fazer grupos e está fundado na posse de um capital simbólico, sendo este considerado uma espécie de crédito (poder atribuído àqueles que obtiveram reconhecimento). Depois há a eficácia simbólica que depende do grau em que a visão proposta esta alicerçada na realidade. Entretanto, toda esta proposta e as premissas que orientam 0 trabalho do autor desembocam-se em dois pontos centrais de sua reflexão, a noção de habitus e a compreensão de campo.

\section{A noção de habitus}

Uma das funções maiores da noção de habitus consiste em descartar dois erros complementares nascidos da visão escolástica: por um lado, o mecanicismo, que sustenta que a ação é o efeito mecânico da coerção por causas externas; por outro lado, o finalismo, que, em particular com a teoria da ação racional, sustenta que o agente atua de forma livre, consciente, e, como dizem alguns utilitaristas, with full understanding, já que a ação é fruto de um cálculo das possibilidades e dos benefícios (BOURDIEU, 1989, pág. 183)

A idéia de habitus foi uma proposta da Escolástica que ficou conhecida por tentar conciliar a Filosofia e a Teologia nas escolas da Idade Média. Esta concebia o habitus como uma disposição estável para se operar numa determinada direção, num processo de repetição, visando criar uma certa naturalidade entre sujeito e objeto na compreensão de que o hábito deveria se constituir na segunda dimensão do homem.

Decorrente desta compreensão reinterpretase a noção de habitus, colocando que este se apresenta como disposição estável para operar numa determinada direção. De modo que através da repetição, conseqüentemente, cria-se certa naturalidade entre sujeito e objeto dando $o$ sentido de que o hábito se tornava uma segunda dimensão do homem, o que efetivamente assegurava a realização da ação considerada.

Se o mundo social tende a ser percebido como evidente e a ser apreendido para empregar os termos de Husserl, segundo uma modalidade dóxica, é porque as disposições dos agentes, o seu habitus, isto é, as estruturas mentais através das quais eles apreendem o mundo social, são em essência produto da interiorização das estruturas do mundo social. (BOURDIEU, 1989, p 158).

As estruturas sociais e as estruturas mentais perpassam todo este processo, abarcando de um lado o objetivismo e de outro o subjetivismo. Dito de outra forma se pode colocar que há uma correspondência entre as estruturas sociais e as estruturas mentais, entre as divisões objetivas do mundo social - dominantes e dominados nos diferentes campos - e os princípios de visão e divisão que os agentes thes aplicam (BOURDIEU, 1991, p. 113).

$\mathrm{Na}$ análise de exploração das estruturas cognitivas (construtivista) os agentes investem nas ações e representações pelas quais constroem a realidade social; enquanto que nas estruturas sociais (estruturalista), estruturas objetivas, a contribuição está na análise dos esquemas de percepção, de apreciação e de ação que os agentes, alunos, assim como professores, põem em ação em seus julgamentos e suas práticas. Posto de outro modo, o discernimento decorrente desse processo aponta para a operação de um habitus, Isto é, de esquemas geradores de classificações e de práticas classificáveis. Portanto, o habitus está vinculado geneticamente e também estruturalmente a esquemas, forma incorporada, e a uma tomada de posição prática sobre este espaço. (BOURDIEU, 1991, p. 114).

A idéia de habitus se apresenta para Bourdieu (1989, 1990a, 1994a, 1994d, 1994e), bem como em estudiosos de seu trabalho (ORTIZ, 1994; WACQUANT, 2007a, 2007b, entre outros como 
um sistema de esquemas para a elaboração de práticas concretas, uma espécie de gramática das ações que serve para diferenciar uma classe de outra no terreno social.

Para o autor, pode-se considerar o habitus como aquilo que se adquiriu, mas que se encarnou de modo durável no corpo sob a forma de disposições permanentes. Habitus seria algo "potencialmente gerador", "um produto dos condicionamentos" que tende a reproduzir a lógica objetiva dos condicionamentos, mas fazendo-a sofrer uma transformação.

Bourdieu (1983, 1989, 1990a, 1990b, 1994b, 1994e) considera que o habitus tende a conformar e orientar a ação, mas, na medida em que é produto das relações sociais, ele tende a assegurar a reprodução dessas mesmas relações objetivas que o engendraram. A interiorização, pelos atores, dos valores, normas e princípios sociais assegura, dessa forma, a adequação entre as ações do sujeito e a realidade objetiva da sociedade como um todo (BOURDIEU, 1989, 1994b, 1996; ORTIZ, 1994; WACQUANT, 2007b).

Trata-se de uma disposição estável para se operar numa determinada direção. Através da repetição, conseqüentemente, cria-se certa naturalidade entre sujeito e objeto dando 0 sentido de que o hábito se tornava uma segunda dimensão do homem, o que efetivamente assegurava a realização da ação considerada. De modo que habitus se define como um sistema de disposições duráveis e transponíveis, estruturas estruturadas dispostas a funcionar como estruturas estruturantes, como princípios geradores e organizadores de práticas e de representações que podem ser objetivamente adaptadas a seu propósito.

Dessa forma, entender o habitus como um conjunto de disposições, decorrentes das estruturas sociais, preparadas para a ação significa falar numa dimensão prática, num sentido prático que apela para um domínio de conhecimento pré-reflexivo, pois o agente orienta sua ação no mundo sem pensá-lo. Portanto, trata-se de uma hipótese construída no papel.

No geral, o habitus pode ser considerado como uma sociologia genética das disposições relacionadas ao agir, sentir, acreditar e pensar e de suas atualizações com a tarefa de ultrapassar a oposição entre sociedade e individuo (LAHIRE, 2002a).

\section{A compreensão de campo (espaço social)}

Bourdieu (1983, 1989, 1990b, 1994c, 1994d, 1994e) chega à noção de campo, como sendo o espaço onde as posições dos agentes se encontram a priori fixadas. O campo se define, assim, como o locus onde se trava uma luta entre os atores em torno de interesses específicos que caracterizam a área em questão. Por exemplo:
(...) o campo das práticas esportivas é o lugar de lutas, pois entre outras coisas disputam o monopólio de imposição da definição legitima da prática esportiva e da função legitima da atividade esportiva, amadorismo contra profissionalismo. No geral este campo está ele também inserido no campo das lutas pela definição do corpo legitimo e do uso legitimo do corpo, lutas que além de oporem entre si, treinadores, dirigentes, professores de ginástica e outros comerciantes de bens e serviços esportivos, opõem também os moralistas... (BOURDIEU, 1983, p. 142),

Para Bourdieu $(1983,1989)$ um "campo" se legitima no exercício de determinadas práticas sociais que formam também um "habitus" em função de um "capital simbólico" que é obtido através de lutas políticas na demarcação de seu território. Porém, o "campo" é definido como um espaço social de relações objetivas, pois...

Os campos se apresentam à apreensão sincrônica como espaços estruturados de posições (ou de postos) cujas propriedades dependem das posições nestes espaços, podendo ser analisadas independentemente das características de seus ocupantes (em parte determinadas por elas) (BOURDIEU, 1983, p. 89).

Dessa forma, o autor chega à noção de campo, como sendo o espaço onde as posições dos agentes se encontram a priori fixadas. O campo se define, assim, como o locus onde se trava uma luta entre os atores sociais em torno de interesses específicos que caracterizam a área em questão. E um espaço onde se manifestam as relações de poder, sempre a partir do "capital social" dos agentes que estão em dois pólos: dominantes e dominados. Dentro dessa perspectiva resolve-se o problema da adequação entre ação subjetiva e objetividade da sociedade, uma vez que todo ator age no interior de um campo socialmente predeterminado.

Bourdieu dedica grande parte de seu trabalho conceituando o que denomina campo de produção de bens culturais e simbólicos, identificando-os abstratamente na sociedade enquanto espaços portadores de especificidades: campo escolar, campo científico, campo artístico, campo político, campo jornalístico etc.

Os campos possuem traços estruturalmente equivalentes ou determinados homologias estruturais e funcionais que lhes proporcionam identificação. Entretanto, possuem especificidades, objetivos e determinadas características que são inerentes e irredutíveis a outros campos. Há em cada um dos agentes (profissionais, grupos e instituições) que se movimentam desenvolvendo ações e práticas sociais e produzindo capital de diferentes espécies e graus de legitimidade.

Os agentes, no interior de cada campo e externamente, vivenciam divergências, conflitos e consensos, tendo como fundamento o quantum de capital simbólico conquistado ou acumulado historicamente. O capital simbólico, como aponta Bourdieu, é 
uma espécie de crédito, refere-se ao poder atribuído àqueles que obtiveram reconhecimento suficiente para ter condições de impor reconhecimento (CANESIN, 2002, p. 97).

Dessa forma, o campo deve ser entendido enquanto espaço objetivo de um jogo, um lugar de luta onde se manifestam e se definem as relações de poder. No interior de cada campo estão reservados espaços para os dominantes (aqueles que possuem um máximo de capital social) e para os dominados (ausência do capital específico que define o campo). Assim, a estrutura de um campo tende a se definir pela conservação ou subversão da estrutura de distribuição do capital específico ou simbólico. Sobre o assunto Lahire (2002b, p.47-48) nos apresenta uma síntese muito clara com relação a compreensão de campo de Bourdieu, com base nas obras "Quelques propriétés des champs" (1980) e "Le champ littéraire" (1991) ao assinalar que:

- Um campo é um microcosmo incluído no macrocosmo constituído pelo espaço social (nacional) global.

- Cada campo possui regras do jogo e desafios específicos, irredutíveis às regras do jogo ou aos desafios dos outros campos (o que faz "correr" um matemático - e a maneira como "corre" - nada tem a ver com o que faz "correr" - e a maneira como "corre" um industrial ou um grande costureiro).

- Um campo é um "sistema" ou um "espaço" estruturado de posições.

- Esse espaço é um espaço de lutas entre os diferentes agentes que ocupam as diversas posições.

- As lutas dão-se em torno da apropriação de um capital específico do campo (o monopólio do capital específico legítimo) e/ou da redefinição daquele capital.

- O capital é desigualmente distribuído dentro do campo e existem, portanto, dominantes e dominados.

- A distribuição desigual do capital determina a estrutura do campo, que é, portanto, definida pelo estado de uma relação de força histórica entre as forças (agentes, instituições) em presença no campo.

- As estratégias dos agentes entendem-se se as relacionarmos com suas posições no campo.

- Entre as estratégias invariantes, pode-se ressaltar a oposição entre as estratégias de conservação $e$ as estratégias de subversão (o estado da relação de força existente). As primeiras são mais freqüentemente as dos dominantes e as segundas, as dos dominados (e, entre estes, mais particularmente, dos "últimos a chegar"). Essa oposição pode tomar a forma de um conflito entre "antigos" e "modernos", "ortodoxos" e "heterodoxos"...

- Em luta uns contra os outros, os agentes de um campo têm pelo menos interesse em que o campo exista e, portanto, mantêm uma "cumplicidade objetiva" para além das lutas que os opõem.

- Logo, os interesses sociais são sempre específicos de cada campo e não se reduzem ao interesse de tipo econômico.
- A cada campo corresponde um habitus (sistema de disposições incorporadas) próprio do campo (por exemplo o habitus da filologia ou o habitus do pugilismo). Apenas quem tiver incorporado o habitus próprio do campo tem condição de jogar o jogo e de acreditar n(a importância d)esse jogo.

- Cada agente do campo é caracterizado por sua trajetória social, seu habitus e sua posição no campo.

- Um campo possui uma autonomia relativa: as lutas que nele ocorrem têm uma lógica interna, mas o seu resultado nas lutas (econômicas, sociais, políticas...) externas ao campo pesa fortemente sobre a questão das relações de força internas.

A teoria dos campos dá continuidade a uma longa tradição de reflexões sociológicas e antropológicas sobre a diferenciação histórica das atividades ou das funções sociais e sobre a divisão social do trabalho. (grifos nossos)

$\mathrm{Na}$ área da educação física Cesana (2005) lembra que é o caso específico daquilo que chamamos de "profissão" que tem como referência um corpo organizado de conhecimento e como princípio regulador desta autoridade 0 conhecimento científico. O interessante é que Bourdieu $(1983,1990)$ remete ao entendimento de que os espaços podem ser analisados pelos espaços estruturados de posições ou postos que podem, por sua vez, ser analisados independentemente de seus ocupantes. Este procedimento identifica a escolha pelo referencial do autor para abordar construções sociais, como as profissões, pois em Bourdieu a estrutura social é definida pelas profissões e os capitais a elas associados.

Por último, para entender o pensamento de Bourdieu em relação às construções sociais surge o termo illusio com um conhecimento pautado no fato de se ter "nascido dentro do campo" ou "do jogo" (filho de jogador de futebol que quer se tornar jogador).

\section{A illusio}

O illusio é uma espécie de conhecimento baseado no fato de ter nascido dentro do jogo, de pertencer ao jogo pelo nascimento: dizer que conheço o jogo desse modo significa que o tenho no sangue, no corpo, que ele joga em mim sem mim; um pouco como quando meu corpo responde a um pontapé antes mesmo de eu 0 ter percebido enquanto tal. (BOURDIEU, 1989b, p. 44 apud LAHIRE, 2002b, p.51).

Entretanto também é possível viver num universo sem ser totalmente possuído por ele, pela illusio específico desse universo, sem entrar em concorrência, sem desenvolver estratégias de conquista do capital específico desse universo. Por exemplo: participar de um universo como praticante amador, simples consumidor ou na qualidade de simples participante na organização material desse universo, sem participar diretamente do jogo que nele se joga, mas investido no interesse e na crença, numa crença compartilhada que efetiva o pertencimento a um campo (espaço social). (LAHIRE, 2002b, PAIVA, 
2003). Esta crença, segundo Cesana (2005, p.83) se traduz por interesse e investimentos que produzem e promovem tal jogo. Considerando:

- $\quad \mathrm{O}$ investimento no jogo jogado em um campo que tira seus agentes do patamar comum, de certa indiferença, e os inclina e dispõe a operar com as distinções pertinentes à lógica do campo e;

- $O$ interesse pelo jogo que valora e legitima as apostas sociais nele geradas. Portanto, a illusio é a condição original de um campo e seu jogo, no qual ela é, ao mesmo tempo, o arbitrário fundador e o produto.

Desta forma, Paiva (2003) observa que o reconhecimento da illusio na obra de Bourdieu busca identificar, pelo menos em parte, o que é capaz de dar unidade ao grupo. Para a autora...

"A construção da especificidade do campo da educação física caminha a par da constituição da illusio já que, para falar em campo, é preciso que se estabeleça e se reconheça um acordo tácito entre agentes e instituições sobre aquilo que merece ser disputado, ou seja, os consensos produzidos acerca da importância do jogo, bem como as formas legítimas de jogá-lo, produzindo assim, a identidade social do grupo

(...) cabe observar que, no caso do reconhecimento da illusio, trata-se de identificar, pelo menos em parte, o que é capaz de dar unidade ao grupo, argüindo as questões que lhe são colocadas - ou as que são por ele assumidas - como sendo suas questões obrigatórias. (PAIVA e RON, 2003, p. 58-59)

Por questões obrigatórias se entende aquela que os homens "ilustrados", de uma determinada época, estão de acordo em discutir mesmo discordando a respeito das questões que discutem, pois sob uma perspectiva histórica é possível perceber como vai se "produzindo a necessidade e a crença de que é preciso delegar a um grupo de especialistas 0 arbítrio acerca das educações do corpo" ( p. 59).

Sobre este assunto vai ser colocado também que, das relações entre os campos, a noção de subcampo auxilia na compreensão desse jogo, pois...

Entendemos que, de fato, a educação física pode ser pensada, em parte, como um subcampo do campo pedagógico e/ou como um subcampo do campo acadêmico. Significa dizer que ela pode ser analisada com base nas formas de organização e comunicação que articulam as práticas e representações que movem esses campos. Entretanto, parece-nos que é justamente a produção de uma especificidade do campo educação física constituída na interface dessas temáticas - e que, portanto, o faz se apropriar e ressignificar a lógica de ambos a partir de interesses que lhe sejam, ou deveriam ser, próprios - que permite não restringi-la ou reduzi-la a um subcampo do campo pedagógico ou do acadêmico, não sucumbindo, assim à facilidade de recortes definitivos que privilegiassem a análise de suas práticas pedagógicas ou científicas. A caracterização da illusio - a crença na necessidade de se arbitrar com legitimidade as questões afetas aos saberes e fazeres corporais pedagogizados e pedagogizáveis, escolares e não escolares - do campo da educação física, mostrou que as pedagogias do corpo nele construídas ou autorizadas só o são com o aval científico; o conhecimento científico que busca discutir especificamente modos de educação física - e não do esporte ou da atividade física - só o podem fazê-lo a partir do olhar pedagógico (PAIVA e RON, 2003, p. 59).

Dessa forma, retomando o que já foi colocado, a especificidade da construção do campo Educação Física caminha a par da constituição da illusio, reconhecendo-se os acordos tácitos entre agentes e instituições sobre aquilo que merece ser disputado, produzindo os consensos acerca da importância do jogo, as formas legitimas de jogá-lo, produzindo a identidade social do grupo.

No geral, há necessidade de identificar e sistematizar a problemática que dá sentido ao campo, o objeto da disputa e os interesses específicos em jogo. $\mathrm{O}$ acordo tácito estabelecido entre os jogadores, o efeito de campo na/da área, os agentes e instituições que disputam e disputaram a construção de legitimidade(s), as estratégias de conservação e subversão adotadas, as formas específicas de organização e comunicação que foram/são acionadas para instaurar/defender o monopólio da legitimidade, o habitus que permite $\mathrm{o}$ conhecimento $\mathrm{e}$ reconhecimento do campo, o capital específico do campo e os bens simbólicos que produz (PAIVA, 2003, p. 65).

\section{O Habitus profissional como hipótese}

Com efeito, nada é menos natural do que o modo de pensamento e de acção que é exigido pela participação no campo político: como o habitus religioso, artístico ou científico, o habitus do político supõe uma preparação especial. É, em primeiro lugar, toda a aprendizagem necessária para adquirir 0 corpus de saberes específicos (teorias, problemáticas, conceitos, tradições históricas, dados econômicos, etc.) produzidos e acumulados pelo trabalho político dos profissionais do presente e do passado ou das capacidades mais gerais tais como o domínio de certa linguagem e de certa retórica política, a do tribuno, indispensável nas relações com os profanos, ou a do debater, necessária nas relações entre profissionais. (BOURDIEU, 1989, p.169)

O exemplo apresentado nos coloca numa relação imediata com a questão da profissão e do exercício profissional, envolvendo um processo anterior, o da iniciação, com suas provas e ritos de passagem na aprendizagem de um habitus. Porém, este processo de passagem exige um domínio prático da lógica imanente daquele 
campo, bem como uma submissão de fato aos valores, às hierarquias e às censuras inerentes a este campo.

O conceito de habitus profissional foi utilizado por Perrenoud et al (1993) para se referir às rotinas construídas pelos professores ao longo de sua trajetória, considerando que este é a "interiorização do exterior". Para o autor o habitus profissional compõe-se de: rotinas (que 0 professor constrói ao longo dos seus anos de trabalho); momento oportuno (a utilização de saberes e representações explícitas capazes de dirigir uma ação); ação racional (utilização de certos conhecimentos, aliados ao raciocínio rápido, em extrema urgência); improvisação regrada (parte imprevista na ação planejada, o agir na urgência).

Nesta direção Sanchotene (2006, p. 270) vão assinalar que o habitus traduz a nossa capacidade de operar, de forma prática, em uma rotina econômica sendo durável, mas não estático ou eterno, bem como não é uma aptidão natural, mas social. De modo que este habitus profissional, por não ser reflexivo, por estar baseado na repetição, nas rotinas e por consolidar algumas regularidades no cotidiano escolar, contribui para o desenvolvimento de um currículo oculto nas aulas e nas escolas.

Na visão de Sanchotene; Molina Neto (2006), com base na leitura de Perrenoud et al (2001), o professor de educação física produz rotinas econômicas que derivam dos saberes práticos. Em outras palavras, práticas que deram certo são incorporadas ao habitus profissional dos professores. Na maioria das vezes, porém, são práticas não questionadas, ou seja, resolvem as situações de forma imediata. Em contrapartida, para que haja a conscientização do habitus profissional é necessário, entre outros aspectos, tempo para a reflexão, possibilitando trazer este habitus para a consciência. Sendo assim, a intensificação dificulta a superação do habitus profissional e favorece a utilização de rotinas e de materiais "pré-fabricados".

Assim, ao trabalhar com a intensificação aliada ao habitus profissional torna-se possível montar uma cena que vai de encontro ao que sugere Perrenoud (1993) em seu estudo sobre as possibilidades de formação de novo habitus profissional. Para o autor, é necessário fazer uma tomada de consciência do habitus, trazê-lo à tona, conhecê-lo: A tomada de consciência muda o habitus porque o combate em tempo real e na situação. Deste modo, a intensificação pode ser considerada fator que dificulta a formação de um novo habitus profissional, influenciando as possibilidades de mudança na prática pedagógica.

Porém, sobre outra perspectiva Tardif et al (1991) procurando identificar e definir quais os saberes que intervêm no habitus profissional, na prática pedagógica dos professores, concluiu que os professores se utilizam, em grande medida, dos saberes da experiência, dos saberes específicos que se fundam nos saberes cotidianos e no conhecimento do meio. São saberes práticos que "incorporam-se à vivência individual e coletiva sob a forma de habitus e de habilidades, de saber fazer e de saber ser" (TARDIF et al, 1991, p. 220). Para o autor os saberes da experiência formam um conjunto de representações a partir das quais os professores interpretam, compreendem e orientam sua profissão e sua prática, e constituem a cultura docente em ação.

No âmbito desse processo a profissão é vista como um campo (espaço social), no sentido dado por Bourdieu (1994d), marcado por uma lógica particular, por hierarquias e por disputas, de onde se torna necessário desvelar os fragmentos invisíveis da constituição de um habitus profissional, visando relativizar as imagens de negligência e incompetência técnica que possam ser atribuídas aos professores.

Neste contexto, Silva (2005) vai afirmar que o habitus é desenvolvido somente no e com o exercício da docência e por isso enfatiza que o ato de ensinar na sala de aula seria melhor denominado por habitus ao invés do termo prática docente.

Para a autora o habitus professoral pode ser organizado por meio de um principio hologramático composto por três elementos que mantém uma relação complexa entre si: ações didáticas, hexis corporal e postura. Há em cada elemento que o compõe "uma referência básica comum a todos que mostra, às vezes mais sutilmente às vezes menos, o tipo de habitus professoral que o conjunto dessas reações organiza" (SILVA, 2007, p. 60).

As ações didáticas dizem respeito diretamente ao domínio que o professor tem do conteúdo, bem como o modo de ensiná-lo. Segundo a autora, essas ações são realizadas por meio do que ela denomina discurso professoral, em que o que importa é o conteúdo deste discurso. Em relação à hexis corporal a autora citando Bourdieu (1983) afirma que:

são movimentos corpóreos que os sujeitos que exercem uma determinada prática laborativa realizam quando a exercem, neste caso professores/as. Esses sujeitos realizam gestos e comportamentos muito parecidos, quase iguais, e os exercem sem que haja um 'acordo' consciente entre eles, mas esses movimentos são harmônicos quando se olha o conjunto desses sujeitos na prática (SILVA, 2007 , p. 66).

Desta maneira, no professor, a héxis corporal surge como mensageiro da qualidade profissional daquele através da "fala corporal", da motivação e disposição. Vale lembrar que a héxis corporal nada tem a ver com a aparência física do professor, mas sim aos movimentos que auxiliam o seu ensino em sala de aula. E por o ultimo a postura do professor que diz respeito aos valores 
que regem suas ações sociais e relacionais. Assim, podemos dizer que a postura, nos três elementos explicitados, é a que aparece de forma mais sutil. Porém, todos estes elementos podem se manifestar simultaneamente, um sobrepondo ao outro ou separadamente.

Dessa forma temos o habitus professoral que, de acordo com Silva (2007), é composto por ações didáticas do docente reveladas por meio do seu discurso professoral; pela hexis corporal representada por movimentos realizados pelo professor como uma ferramenta que auxilia o seu ensino em sala de aula e pela postura do professor manifestada através dos valores que norteiam suas ações de um modo geral.

\section{A guisa de conclusão algumas questões sobre o habitus}

Os primeiros trabalhos acerca do habitus professoral tiveram início no fim da década de 80, sendo um re-significação desse conceito. No âmbito desses estudos outro conceito que influenciou na elaboração do habitus professoral foi a noção de experiência formulada por Edward Palmer Thompson, em 1981, bem como os estudos realizados a respeito dos saberes docentes por Maurice Tardif em 2002 (SILVA, 2005). Porém, o pioneiro foi Perrenoud (1993, p. 21) ao assinalar que "a profissão é composta por rotinas que o docente põe em acção de forma relativamente consciente, mas sem avaliar o seu caráter arbitrário, logo sem as escolher e controlar verdadeiramente".

No dia-a-dia estes "esquemas" nas ações dos professores mais experientes funcionam eficazmente, mas não são organizados de forma consciente. Esta falta de necessidade em organizar as ações conscientemente faz com que os professores mais experientes não consigam também mais se lembrar de que maneira suas ações pedagógicas foram fundamentadas.

Knoblauch (2005), concordando com Perrenoud (1993), afirma que o habitus docente produz e regula práticas sem obediência consciente a regras, adaptando-as a seu fim, sem o conhecimento desta finalidade. $\mathrm{O}$ agente social, neste caso o docente, é construído por meio de reestruturações constantes de suas ações, gerando novas experiências que são integradas ao seu habitus inicial. Por conseguinte, a autora coloca que mesmo que uma instituição de ensino tenha passado por diversas modificações estratégicas de intervenção, há um conjunto de esquemas fortemente instalado no interior da escola, denominado cultura escolar, que ao ser incorporado pelos professores pode ser encarado como facetas do "habitus docente constitutivo da profissão” (p. 11).

Townsend e Tomazzeti (2007) corroborando com o assunto, afirmam que o habitus professoral (ou docente) é composto por dois "sub-habitus": o habitus rotinizado e o habitus reflexivo. O primeiro diz respeito à "constância, automatismo, porque não envolve a utilização consciente do uso dos esquemas de pensamento" (p. 211); o segundo "envolve a necessidade de um trabalho mental a partir da natureza das ações realizadas e dos desafios confrontados em determinado contexto, abrangendo a consciência, isto é, um pensar sobre os motivos da sua ação, a partir do uso de uma sabedoria prudente" (p. 212).

Para fins de exemplificação, o professor ao realizar a ação de um atendimento individualizado a um aluno com dificuldades deixa transparecer naquele momento a faceta do habitus rotinizado e ao pensar sobre o exercício da ação realizada, no instante em que ela está ocorrendo ou posteriormente a ela, manifesta naquele momento a faceta do habitus reflexivo (TOWNSEND e TOMAZZETI, 2007). Assim,

O habitus é a 'gramática geradora das práticas', o sistema de esquemas que orientam tanto a improvisação (na ilusão da espontaneidade) como a acção planificada, tanto a evidencia como a dúvida metódica, tanto a invenção de novas estratégias como a concretização de esquemas e receitas, tanto as condutas inconscientes ou rotineiras como as decisões (PERRENOUD, 1993, p. 24, grifo nosso)

Portanto, a importância do habitus deriva do fato de se poder "pensar e analisar um conjunto coerente de disposições subjetivas - capazes, simultaneamente, de estruturar representações e gerar práticas - como o produto de uma história". Como o produto de uma seqüência necessariamente heterogênea de condições objetivas que define "a trajetória dos indivíduos como movimento único através de campos sociais, tais como a família de origem, o sistema escolar ou o universo profissional". (DUBAR, 1997, p. 74).

Neste contexto trabalhar com a questão da docência em si, vinculada a compreensão dos saberes docente na trajetória de vida pessoal (e profissional) do professor, bem como com a inferência de que esta também trás subjacente a ela um habitus, pode nos auxiliar na decodificação dessa identidade.

\section{Referências}

ALTET. M. As competências do professor profissional: entre conhecimentos, esquemas de ação e adaptação, saber analisar. In: PAQUAY. L; et al. (Org..). Formando professores profissionais: Quais estratégias? Quais competências? Porto Alegre: Artmed, 2001. p.2335.

\section{BENITES, L. C. Identidade do Professor de Educação Física. Um estudo sobre os saberes docentes e a prática pedagógica. Rio Claro, SP: Unesp, 2007.}

BOURDIEU, P. Algumas propriedades dos campos. In: Questões de Sociologia. Rio de Janeiro: Marco Zero, 1983, p. 89 - 94. 
BOURDIEU, P. Capítulo III: A gênese do conceito de habitus e de campo. In.: O poder simbólico. Rio de Janeiro/RJ: Bertrand Brasil, 1989.

BOURDIEU,P. Estruturas sociais e estruturas mentais. Revista \& Educação, 3, p. 113 - 119, 1991.

BOURDIEU, P Gostos de classe e estilos de vida. In: ORTIZ, R. (org.). Pierre Bourdieu: sociologia. São Paulo: Ática, 1994a, p. 01-81.

BOURDIEU, P Gostos de classe e estilos de vida. In: ORTIZ, R. (org.). Pierre Bourdieu: sociologia. São Paulo: Ática, 1994b, p. 82-121.

BOURDIEU, P O campo científico. In: ORTIZ, R. (Org.). Pierre Bourdieu: sociologia. São Paulo: Ática, 1994c, p. 122-156.

BOURDIEU, P. A economia das trocas lingüísticas. In: ORTIZ, R. (Org.). Pierre Bourdieu: sociologia. São Paulo: Ática, 1994d, p. 156-183.

BOURDIEU, P. Razões práticas: sobre a teoria da ação. Tradução de Mariza Corrêa. Campinas: Papirus, 1996.

BOURDIEU, P. Economia das trocas simbólicas. 6 edição. São Paula: Perspectiva, 2007.

CANESIN, M. T. A fertilidade da produção sociológica de Bourdieu para ciências sociais e educação. In: ROSA, D. E.G. e SOUZA, V. C. (Org.) Didáticas e práticas de ensino: interfaces com diferentes saberes e lugares formativos. Rio de Janeiro, RJ: DP\&A, 2002, p. 85-101.

\section{CESANA, J.. O Profissional de Educação} Física e as Práticas corporais alternativas: Interações Ocupacionais. 2005. Dissertação (Mestrado em Ciências da Motricidade) - Instituto de Biociências, Universidade Estadual Paulista, Rio Claro, 2005.

CHAIM JUNIOR, C. I. Cultura corporal juvenil da periferia paulistana: subsídios para a construção de um currículo de educação física. 2007. 130 p. Dissertação de mestrado. Faculdade de Educação. Universidade de São Paulo, São Paulo, 2007.

COELHO, E. C. As profissões imperiais: medicina, engenharia e advocacia no Rio de Janeiro, 1822 - 1930. Rio de Janeiro, RJ: Record, 1999.

CONTRERAS, J. Autonomia de professores. São Paulo, SP: Cortez, 2002.
DUBAR, C. A socialização: construção das identidades sociais e profissionais. Porto, $\mathrm{Pt}$ : Porto Editora, 1997.

FERNANDEZ ENGUITA, M. A ambigüidade da docência: entre o profissionalismo e a proletarização. Revista Teoria e Educação, Porto Alegre, v. 4, p. 41 - 61, 1991.

\section{FREIDSON, E. Renascimento do}

Profissionalismo: Teoria, Profecia e Política. São Paulo, SP: Editora Universidade São Paulo, 1998.

IMBERNÓN, F. Formação docente profissional: forma-se para a mudança e a incerteza. São Paulo: Cortez, 2004.

KNOBLAUCH, A. A incorporação do habitus e a dimensão cultural da formação de professores.

VIII Congresso Estadual Paulista sobre Formação de Educadores - Dimensão cultural na formação de professores / organizadores: Comissão Organizadora do Livro Eletrônico - São Paulo: Universidade Estadual Paulista, PróReitoria de Graduação, p. 04 - 12, 2005.

LAHIRE, Bernard. Ensaios sobre Pierre Bourdieu. Educação \&. Sociedade. [online], vol.23, n.78, pp. 11-13, 2002

LAHIRE, Bernard. Reprodução ou prolongamentos críticos?. Educação \&. Sociedade. [online], vol.23, n.78, pp. 37-55, 2002b.

ORTIZ, R. A procura de uma sociologia da prática. In: ORTIZ, R (Org). Pierre Bourdieu. Coleção Grandes Cientistas Sociais. São Paulo: Ática, 1994, p. 7-37 n. 39.

PAIVA, F. S. L. Constituição do Campo da educação física no Brasil: Ponderações acerca de sua especificidade e autonomia. In.: BRACHT, $\mathrm{V}$; CRISORIO, R(org). A educação física no Brasil e na Argentina: identidade, desafios e perspectivas. Campinas/SP: Autores Associados, 2003. p.63.

PAIVA, F. S. L.; RON, O. O. Parte II. A constituição do campo da educação Física. Introdução. In.: BRACHT, V; CRISORIO, R(org). A educação física no Brasil e na Argentina: identidade, desafios e perspectivas. Campinas/SP: Autores Associados, 2003, p.57.

PAPI, S. O. G. Professores: formação e profissionalização. Araraquara: Junqueira e Marin, 2005.

PERRENOUD. P. Práticas pedagógicas, profissão docente e formação: perspectivas 
sociológicas. Lisboa, Pt: Publicações Dom Quixote, 1993.

PERRENOUD, P. et al. (Orgs.). Formando professores profissionais: quais estratégias? quais competências? Porto Alegre: Artmed, 2001.

PIMENTA, S. G. A formação de professores: saberes da docência e identidade. Nuances, Presidente Prudente, v.3, p.5-14, 1997.

PINTASSILGO, J. O mestre como artesão/prático e como intelectual. In: MAGALHÃES, J.; ESCOLANO, A. Os professores na história. Porto, Pt: Lusografe, p. 83 - 100, 1999.

SANCHOTENE, M. U.; MOLINA NETO, V. Habitus profissional, currículo oculto e cultura docente: perspectivas para a análise da prática pedagógica dos professores de Educação Física. Revista Pensar a Prática. Goiânia. V. 9, N. 2, p. 267-280, jul./dez. 2006.

SETTON, M. G. J. A teoria do habitus em Pierre Bourdieu: uma leitura contemporânea. Revista Brasileira de Educação: Rio de Janeiro, RJ, n. 20, p. 60-70, maio/junho/julho/agosto 2002.

SILVA, M. da. O habitus professoral: o objeto dos estudos sobre $o$ ato de ensinar na sala de aula.

Revista Brasileira de Educação: Rio de Janeiro, RJ, n. 29, p. 152-163, agosto/2005.

SILVA, M. da. Modos de ser professor: o princípio hologramático na organização do habitus professoral. VIII Congresso Estadual Paulista sobre Formação de Educadores - Modos de ser educador: artes e técnicas - ciências e políticas / organizadores: Comissão Organizadora do Livro Eletrônico - São Paulo: Universidade Estadual Paulista, Pró-Reitoria de Graduação, p. $66-74,2007$.

TARDIF, M. Saberes docentes e formação profissional. Petrópolis, RJ: Vozes, p.31-35, 2002.

TARDIF, M; RAYMOND, D. Saberes, tempo do trabalho no magistério. Revista Educação \& Sociedade, Campinas, n. 73, p. 209-244, 2000.

TOWNSEND, C. B.; TOMAZZETI, E. M. A mobilização de saberes nas práticas de professores nos anos iniciais: um estudo de caso. Educar em Revista: Curitiba, PR: n. 29, p. 207221, 2007.

WACQUANT, L. Lendo o "capital de Bourdieu. Educação \& Linguagem, ano 10, n. 16, jul-dez., p. 37-62, 2007a.
WACQUANT, L. Esclarecer o habitus. Educação \& Linguagem, ano 10, n. 16, jul-dez., p. 63-71, $2007 b$

Esse artigo foi apresentado no IV Seminário de Estudos e Pesquisas em Formação Profissional no Campo da Educação Física- NEPEF, realizado na UNESP/Bauru de 20 a 23 de novembro de 2008.

Endereço:

Samuel de Souza Neto

Av. 24-A, 1515 - Bela Vista

Rio Claro SP Brasil

13505-050

Fone/Fax: (19) 3526-4276

e-mail: samuelsn@rc.unesp.br

Recebido em: 30 de setembro de 2008. Aceito em: 1 de novembro de 2008.

Motriz. Revista de Educação Física. UNESP, Rio Claro, SP, Brasil - elSSN: 1980-6574 - está licenciada sob Licenca Creative Commons 